\title{
Neratinib Maleate
}

National Cancer Institute

\section{Source}

National Cancer Institute. Neratinib Maleate. NCI Thesaurus. Code C136891.

The maleate salt form of neratinib, an orally available, quinazoline-based, irreversible inhibitor of both the receptor tyrosine kinases (RT Ks) human epidermal growth factor receptor 2 (HER2; ERBB2) and human epidermal growth factor receptor (EGFR), with potential antineoplastic activity. Upon administration, neratinib targ ets and covalently binds to the cysteine residue in the ATP-binding pockets of both HER2 and EGFR. This inhibits their activity and results in the inhibition of downstream signal transduction events, induces cell cycle arrest, apoptosis and ultimately decreases cellular proliferation in HER2- and EGFR-expressing tumor cells. EGFR and HER2, RT Ks that are mutated or overactivated in many tumor cell types, play key roles in tumor cell proliferation and tumor vascularization. 